\title{
Cross-reactivity between antigens from Amblyomma cajennense and A. hebraeum (Acari: Ixodidae)
}

\author{
M Hlatshwayo ${ }^{a^{*}}$, M J P Szabób ${ }^{b}, G$ H Bechara ${ }^{b}$ and P A Mbati ${ }^{a}$
}

\begin{abstract}
Laboratory animals exposed to feeding ticks develop resistance which is reflected by a decline in tick engorgement weight, egg-laying by adults and reduced egg viability. Serum antibodies from these hosts and their reaction with tick antigens have been detected by different methods, including precipitation techniques, immunofluorescent techniques, ELISA and Western blots. However, little is known about the effects of antibodies on ticks that engorge on resistant hosts, or which tissues of the tick body are possibly immunogenic. Some researchers, using immunohistochemistry, have detected host antibodies in the gut, salivary glands and haemolymph of ticks engorged on resistant animals. The same technique has helped considerably in determining antigenic sites or antibody targets in other arthropods. Consequently, immunohistochemistry techniques were used in this study to detect cross-reactivity between sera raised against Amblyomma cajennense (Fabricius, 1787) with Amblyomma hebraeum (Koch, 1844), and vice versa. The results show the existence of shared antigens between the 2 tick species. In general, our results point more to a 1-way cross-reactivity of $A$. hebraeum with $A$. cajennense than a reciprocal crossreactivity, suggesting that $A$. hebraeum is more immunogenic than $A$. cajennense.
\end{abstract}

Key words: Amblyomma cajennense, Amblyomma hebraeum, antigens, cross-reactivity.

Hlatshwayo M, Szabó M J P, Bechara G H, Mbati P A Cross-reactivity between antigens from Amblyomma cajennense and A. hebraeum (Acari: Ixodidae). Journal of the South African Veterinary Association (2004) 75(1) 40-42 (En.). Parasitology Research Programne, Department of Zoology and Entomology, Qwa-Qwa Campus, University of the Free State, Private Bag X13, Phuthaditjhaba, 9866 South Africa.

\section{INTRODUCTION}

Ticks are of medical as well as veterinary importance. As vectors of human diseases, they have been ranked 2nd to mosquitoes. As vectors of animal diseases they are considered to be the most important arthropods. Since they are obligatory blood-sucking ectoparasites with lengthy and physiologically slow life cycles, they constitute very important vectors and reservoirs of rickettsia, spirochaetes, protozoa, bacteria and viruses. The control of ticks has been a major concern because of the very high costs of chemical methods of control usually practiced, the environmental contamination it causes, and the development of tick resistance to parasiticides.

It is well established that various species of ixodid ticks induce a degree of resistance in the host and that resistance is immunologically mediated $^{14}$. The nature

aParasitology Research Programme, Department of Zoology and Entomology, Qwa-Qwa Campus, University of the Free State, Private Bag X13, Phuthaditjhaba, 9866 South Africa.

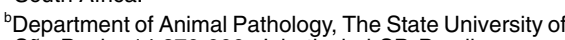
São Paulo, 14.870-000, Jaboticabal-SP, Brazil.

*Author for correspondence.

E-mail: hlatshwayom@ qwa.uovs.ac.za

Received: March 2003. Accepted: February 2004. of the immunological response following tick infestation varies with the tick-host model. This aspect has been comprehensively reviewed. ${ }^{3,13}$

Laboratory animals repeatedly infested with some tick species have been reported to acquire natural immunity manifested by decreased engorgement weight and decreased number of feeding ticks ${ }^{7}$. Generally, each of the authors reported more profound effects with increasing numbers of successive infestations.

Serum antibodies from both naturally infested and immunised hosts and their reaction with tick antigens have been detected by different methods, including precipitation $^{8}$ immunofluorescence $^{1}$ and Western blots ${ }^{4}$. However, little is known about the effects of antibodies on ticks that engorge on resistant hosts, or which tissues of the tick body are possibly immunogenic. Some researchers, using immunohistochemistry, have detected host antibodies in the gut, salivary glands and haemolymph of ticks engorged on resistant animals ${ }^{1,17}$. The same technique has helped considerably in determining antigenic sites or antibody targets in $\operatorname{arthropods}^{2,6}$. In the light of these studies, we have used these techniques in order to detect the antigenic sites and cross-reactivity between sera raised against Amblyomma cajennense and A. hebraeum.

\section{MATERIALS AND METHODS}

\section{Ticks}

Amblyomma hebraeum ticks were obtained from a colony maintained in the humidity chamber $\left(26^{\circ} \mathrm{C} ; 85 \% \mathrm{RH}\right)$ at the University of the Free State, Qwa-Qwa Campus (UNIQWA) South Africa. The A. cajennense ticks were from a colony maintained in a biochemical oxygen-demand incubator $\left(29^{\circ} \mathrm{C} ; 85 \% \mathrm{RH}\right)$ at the Department of Animal Pathology, State University of São Paulo (UNESP), Jaboticabal-SP, Brazil.

\section{Rabbits}

Rabbits aged 2-4 months were used throughout the experiments. The animals were fed a commercial pellet diet and water ad libitum. One group of animals was maintained in the UNIQWA Animal house and the other group in the UNESP Bioterium. The control sera used in the immunoassays were obtained from naive rabbits.

\section{Infestation procedure}

The infestations of rabbits were carried out as described previously by Szabó ${ }^{17}$ with some modifications. Acrylic feeding chambers with a screw-top lid were glued onto the animal's backs. Twelve ticks of each species ( 6 females and 6 males) were used per host animal. Serum was collected before and after tick infestation by means of cardiac puncture.

\section{Histological analysis}

Ticks were fixed in Bouin-Dubocsq fixative for $24 \mathrm{~h}$ and sectioned through a longitudinal sagittal plane after the legs had been amputated for better penetration of the fixative. The ticks were processed, paraffin-embedded, 3-4 $\mu \mathrm{m}$ sections were cut in a microtome, and stained with haematoxilin and eosin, Giemsa and Masson's trichrome stain, in the Department of Animal Pathology, UNESP. This was done in order to study the histology of the tick. Sections of adult female and 
male unfed and partially fed $A$. hebraeum ticks were used for immunohistochemical analysis.

\section{Immunohistochemical analysis}

Unstained sections of unfed ticks were used for the indirect immunohistochemical assay previously described by Manyasi ${ }^{9}$. Tick sections in triplicate were first de-parafinised and rehydrated in xylene, alcohol and tap water. The slides were then washed in PBS. This was followed by the inactivation of the endogenous tissue peroxidase with $\mathrm{DAKO}^{\circledR}$ Peroxidase Blocking reagent (DAKO Corporation, Carpinteria, CA, USA) for $15 \mathrm{~min}$. In addition, slides were incubated for $1 \mathrm{~h}$ with the DAKO ${ }^{\circledR}$ Protein Block Serum-Free reagent to prevent non-specific staining. The sections on the slide were incubated for $1 \mathrm{~h}$ with different concentrations of the primary antibody raised in rabbits (1:50 and 1:100). After several washes, the material was incubated for $30 \mathrm{~min}$ with biotinilated goat anti-rabbit IgG (1:300) $\left(\mathrm{DAKO}^{\circledR}\right)$. After several washes, it was incubated with streptavidin peroxidase for $30 \mathrm{~min}$ and washed. Finally, the sections were incubated with a substrate $\left(D{ }^{\circledR} O^{\circledast}\right.$ Liquid DAB substrate-chromagen system) for a few seconds. The reaction was stopped by washing with distilled water followed by tap water. The sections were then counter-stained with Harris haematoxilin for 30-60 sec and washed with tap water. The sections were dehydrated in alcohol and xylene, and the slides mounted with Glycergel mounting medium $\left(\mathrm{DAKO}{ }^{\circledR}\right)$.

The final result of this enzymatic reaction was the development of a brown colour in the structures to which the swine anti-rabbit peroxidase conjugated antibody had bound. The activity was scored as follows: + , light brown; ++ , dark brown, and both considered positive. When the tissue presented the same colour as the negative control, it was considered negative and indicated by $(-)$ in Tables 1-3. Each serum was tested at least twice.

\section{RESULTS}

Data for the indirect test using sections from unfed ticks of each species with various sera from naive and infested hosts are summarised in Tables 1-3.

The data in Table 1 indicate that sera from rabbits naturally infested with $A$. hebraeum reacted positively with most of the internal organs of this tick species, including malpighian tubules and haemolymph. It is noteworthy that serum obtained from rabbits infested with $A$. hebraeum also reacted positively with some internal organs from $A$. cajennense
Table 1: Indirect immunohistochemistry of sections of unfed adult Amblyomma hebraeum ticks incubated with sera from naive and infested rabbits.

\begin{tabular}{lcc}
\hline Structure & Naive rabbit serum & Infested rabbit serum $^{\star}$ \\
\hline Midgut & & + \\
Epithelial cells & - & ++ \\
Lumen & ++ & + \\
Basement membrane & - & + \\
Haemolymph cells & - & - \\
Salivary glands & & ++ \\
Ducts & - & ++ \\
Type I acini & - & ++ \\
Type II acini & - & + \\
Type III acini & - & \\
Synganglion & - & ++ \\
Muscle & & + \\
Basement membrane & - & - \\
Malpighian tubules & - & ++ \\
Epithelial cells & - & - \\
Lumen & - & + \\
Basement membrane & - & + \\
Ovary & & \\
Basement membrane & - & +
\end{tabular}

${ }^{*}$ Result of enzymatic reaction: + = light brown; ++ = dark brown; - = same colour as negative control.
(Table 2). A few internal organs from $A$. hebraeum reacted positively to sera from rabbits infested with $A$. cajennense as shown in Table 3.

\section{DISCUSSION}

Our results showed the existence of shared antigens between $A$. cajennense \& A. hebraeum. The sera raised against both tick species reacted with the salivary glands in both ticks. Hard ticks require a long time to engorge, and to make this possible they have developed a sophisti-
Table 2: Indirect immunohistochemistry of sections of unfed adult Amblyomma cajennense ticks incubated with sera from naive rabbits and those infested with Amblyomma hebraeum.

\begin{tabular}{lcc}
\hline Structure & Naive rabbit serum $^{*}$ & Infested rabbit serum $^{*}$ \\
\hline Midgut & & + \\
Epithelial cells & - & - \\
Lumen & - & + \\
Basement membrane & - & - \\
Haemolymph cells & - & - \\
Salivary glands & & + \\
Ducts & - & + \\
Type I acini & - & + \\
Type II acini & - & - \\
Type III acini & - & - \\
Synganglion & - & - \\
Muscle & & - \\
Basement membrane & - & - \\
Malpighian tubules & - & - \\
Epithelial cells & - & - \\
Lumen & - & \\
Basement membrane & - & \\
Ovary & & \\
Basement membrane & &
\end{tabular}

*Result of enzymatic reaction: + = light brown; ++ = dark brown; - = same colour as negative control. cated feeding behaviour, based on a varied salivary secretion repertoire that enables them to obtain an appropriate meal $^{3}$. Within this context, antibody containing sera from tick-infested hosts are expected to recognise salivary gland tissues efficiently. Walker and Fletcher ${ }^{12}$, studying the diversity of responses of Rhipicephalus appendiculatus salivary glands depending on the degree of host resistance, concluded that salivary glands are capable of responding selectively to diverse conditions at the feeding site. 
Table 3: Indirect immunohistochemistry of sections of unfed adult Amblyomma hebraeum ticks incubated with sera from naive rabbits and those infested with Amblyomma cajennense.

\begin{tabular}{|c|c|c|}
\hline Structure & Naive rabbit serum* & Infested rabbit serum* \\
\hline \multicolumn{3}{|l|}{ Midgut } \\
\hline Epithelial cells & - & + \\
\hline Lumen & + & + \\
\hline Basement membrane & - & ++ \\
\hline Haemolymph cells & - & + \\
\hline \multicolumn{3}{|l|}{ Salivary glands } \\
\hline Ducts & - & - \\
\hline Type I acini & - & ++ \\
\hline Type II acini & - & + \\
\hline Type III acini & - & + \\
\hline Synganglion & - & - \\
\hline \multicolumn{3}{|l|}{ Muscle } \\
\hline Basement membrane & - & + \\
\hline \multicolumn{3}{|l|}{ Malpighian tubules } \\
\hline Epithelial cells & - & - \\
\hline Lumen & - & - \\
\hline Basement membrane & - & - \\
\hline \multicolumn{3}{|l|}{ Ovary } \\
\hline Basement membrane & - & - \\
\hline
\end{tabular}

*Result of enzymatic reaction: + = light brown; ++ = dark brown; - = same colour as negative control.

This is probably a refined evasion technique used by ticks in order to immunomanipulate host response, and relying on their degree of immunity. Moreover, tick salivary gland-derived material can modulate host cytokine, antibody and cell-mediated immune responses ${ }^{15}$.

Midguts of $A$. cajennense reacted more strongly against sera raised against $A$. hebraeum, whereas midguts of $A$. hebreaum reacted poorly against sera raised against A. cajennense. It appears as though structures of $A$. hebraeum tick gut may act as good immunogens. In this respect, researchers have used purified proteins of the tick midgut to immunise hosts against ticks ${ }^{5,16}$. It should be noted that salivary gland acini type I were always positive. The reason for this is difficult to explain since these acini have an osmoregulatory function and have a lesser or no role during tick feeding. Their intervention in the process of feeding is unknown ${ }^{11}$.

Sera from rabbits infested with $A$. hebreaum, against its sections reacted with more intensity on the majority of structures, which was the case with other similar studies on different tick species ${ }^{2,9}$.

In general, our results point to a 1-way cross-reactivity of $A$. hebraeum with $A$. cajennense rather than a reciprocal crossreactivity, suggesting that $A$. hebraeum is more immunogenic than $A$. cajennense.
Biological Research 27: 697-707

3. Brown S J 1985 Immunology of acquired resistance to ticks. Parasitology Today 1: 166-171

4. Brown S J 1988 Western blot analysis of Amblyomma americanum-derived stagespecific and shared antigens using serum from guinea-pigs expressing resistance. Veterinary Parasitology 28: 163-171

5. Essuman S, Hassanali A, Nyindo M, OleSitayo E N 1992 Augmentation of host's naturally acquired immunity by solubilized membrane-bound midgut proteins of the tick Rhipicephalus appendiculatus. Journal of Parasitology 78: 466-470

6. Ferreira B R, Machado R Z, Bechara G H 1996 Western blot analysis of tick antigens from a Rhipicephalus sanguineus unfed larval extract and identification of antigenic sites in tick sections using immunohistochemistry. A comparative study between resistant and susceptible host species. Veterinary Parasitology 62: 161-174

7. Fivaz B H, Norval A 1989 Observations on successive infestations of the rabbit host by the ticks Rhipicephalus appendiculatus and $R$. zambeziensis (Acari: Ixodidae). Experimental and Applied Acarology 1: 267-279

8. Heller-Haupt A, Varma M G R, Rechav Y, Langi A O, Trider P K E 1987 Immunization of laboratory animals against the tick Amblyomma variegatum using homogenates from unfed larval ticks. Medical Science Research 15: 1371-1372

Sera raised against $A$. hebraeum, when tested with an indirect immunohistochemistry assay, clearly showed that tick-resistant rabbits can certainly recognise probable antigenic sites in tick tissues. Further studies are needed to isolate and characterise the potential antigens identified in this study and to assay their ability to immunise rabbits against tick feeding.

\section{ACKNOWLEDGEMENTS}

The authors are grateful to the staff in the Department of Veterinary Pathology, State University of São Paulo, Brazil, and the Parasitology Research Programme, Qwa-Qwa Campus, University of the Free State. This study formed part of $\mathrm{M}$ Hlatshwayo's postgraduate research fellowship at the State University of São Paulo in Brazil sponsored by the National Research Foundation, Pretoria Other funds were made available by FAPESP via Prof. Bechara's research fund (Fundação de Amparo à Pesquisa do Estado do São Paulo, Brazil).

\section{REFERENCES}

1. Ackerman S, Clare F B, McGill T W, Sonenshine DE 1981 Passage of host serum components, including antibody, across the digestive tract of Dermacentor variabilis. Journal of Parasitology 67: 737-740

2. Almeida A P G, Bechara G H, Varma M G R 1994 Cross-reactivity between hard tick antigens. Brazilian Journal of Medical and immunocytochemistry of the tick bite lesions. PhD thesis, University of London

10. Szabó M P J 1991 Aspectos da imunopatologia comprada em cães, hamsters e cobaias a carrapatos Rhipicephalus sanguineus (Latreille 1806). MS thesis, Universidade de São Paulo

11. Walker A R, Fletcher J D, Gill H S 1985 Structural and histochemical changes in the salivary glands of Rhipicephalus appendiculatus during feeding. International Journal of Parasitology 15: 81-100

12. Walker A R, Fletcher J D 1990 Skin test to detect resistance of cattle to Rhipicephalus appendiculatus ticks. Medical and Veterinary Entomology 4: 321-325

13. Wikel S K 1984 Immunomodulation of host responses to ectoparasite infestation. An overview. Veterinary Parasitology 14: 321-339

14. Wikel S K, Allen J R 1982 Immunological basis of host resistance to ticks. In Obenchain F D, Galun R (eds) Physiology of ticks. Pergamon, Oxford: 169-196

15. Wikel S K, Ramanchandra R N, Bergman D K 1994 Tick-induced modulation of the host immune response. International Journal of Parasitology 24: 59-66

16. Willadsen P, Riding G A, McKenna R V, Kemp D H, Tellman R L, Nielsen J N, Lahnstein J, Cobon G S, Gough J M 1989 Immunological control of a parasitic arthropod. Identification of a protective antigen from Boophilus microplus. Journal of Immunology 143: 1346-1351

17. Wheeler C M, Coleman J L, Benach J L 1991 Salivary gland antigens of Ixodes dammini are glycoproteins that have interspecies cross-reactivity. Journal of Parasitology 77: 965-973
9. Manyasi D 1987 The histopathology and 